\title{
DISCURSO RACISTA DE LAS ÉLITES Y SU IMPACTO EN LAS POLÍTICAS PÚBLICAS
}

\author{
Esther Parra Ramírez
}

Doctorado en Estudios Políticos (en curso), Universidad de Barcelona (España); Magíster en Estudios Políticos, Pontificia Universidad Javeriana (Colombia); Historiadora, Universidad Industrial de Santander (Colombia). Docente Escuela Superior de Administración Pública ESAP (Bucaramanga - Colombia).

E-mail: estherparraramirez@gmail.com

\section{Resumen}

Este artículo busca a partir del análisis del racismo y del discurso de las élites realizado por Teun A. Van Dijk, mostrar que el dominio étnico y el racismo son un problema central en la sociedad occidental actual; que el racismo no consiste únicamente en las ideologías de supremacía racial expresadas en agresiones evidentes, sino que de manera sutil está presente en la opiniones, actitudes e ideologías de la cotidianidad que se manifiestan a través del discurso político, corporativo, mediático y educativo. A su vez se pretende destacar los efectos de texto y habla sobre las políticas públicas y su incidencia directa sobre los diversos grupos minoritarios en países democráticos.

\section{Palabras clave}

Racismo, políticas públicas, ideologías, elites, discurso político, grupos minoritarios, derechos humanos.

\begin{abstract}
This article wants to show, from the analysis of racism and of the speech of the elites realised by Teun A. Van Dijk, that the ethnic dominion and racism still is a central problem in the present western society; that racism does not consist solely of the expressed ideologies of racial supremacy in evident aggressions, but of subtle way is present in the opinions, attitudes and ideologies of the daily, that declare through the political, corporative, media and educative speech. It is tried to emphasize the text effects and, as well, speaks effects on the public policies and their direct incidence on the diverse minority groups in democratic countries.
\end{abstract}

\section{Key Words}

Racism, public policies, ideologies, elites, political speech, minority groups, human rights. 


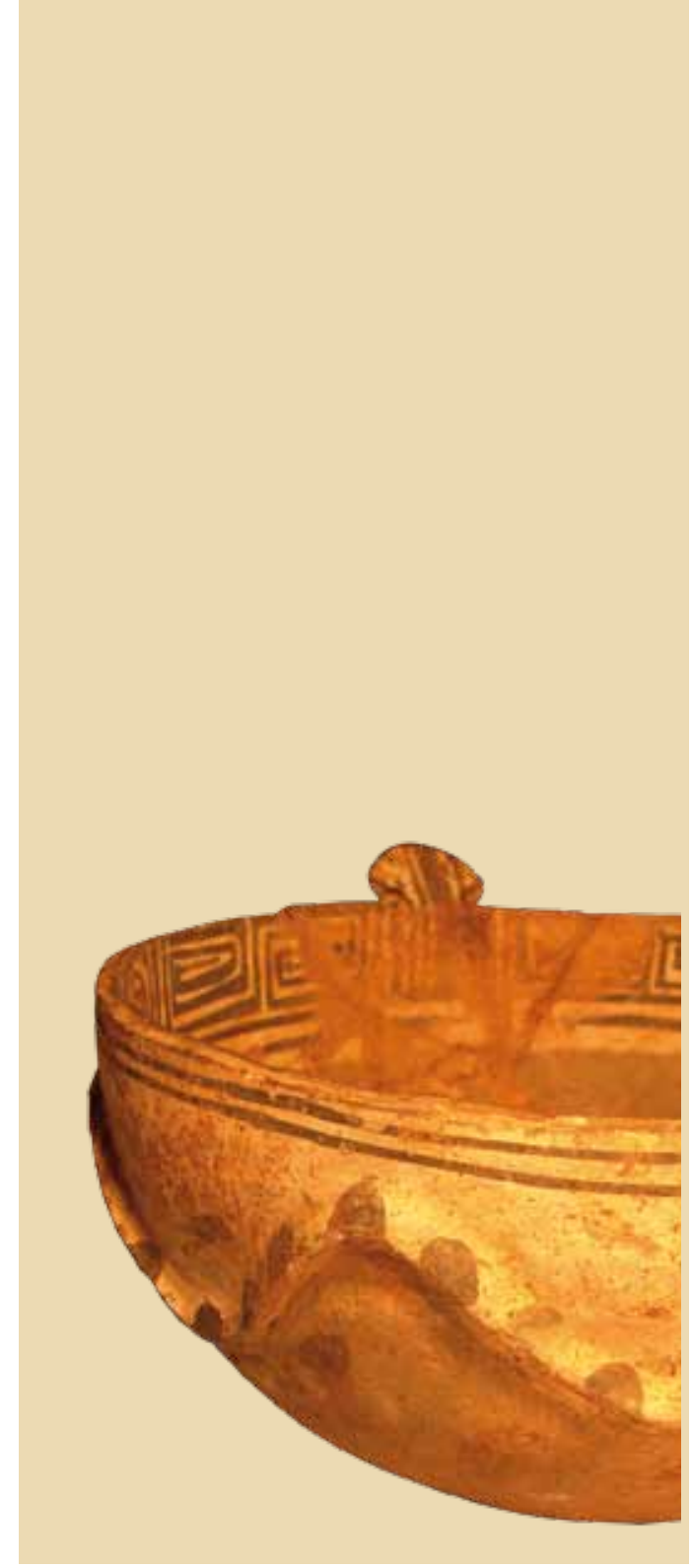

Detalle Figura 


\section{DISCURSO RACISTA DE LAS ÉLITES Y SU IMPACTO EN LAS POLÍTICAS PÚBLICAS*}

Esther Parra Ramirez

\section{INTRODUCCIÓN}

Dado su impacto en la sociedad multicultural de comienzos del Siglo XXI, se hace necesario profundizar en torno al papel que juegan los decisores públicos que desde o con el apoyo de los partidos políticos, los medios de comunicación, las empresas y la academia afectan directamente, por medio del discurso, las agendas públicas en torno a los temas relacionados con las minorías tanto en Estados Unidos como en algunos países de Europa.

Con el fin de analizar la temática se ha dividido este trabajo en dos partes, en la primera, se realiza una síntesis del texto "Racismo y discurso de las Élites" de Teun A. Van Dijk, y se destacan las ideas centrales que estructuran la obra y, en la segunda parte de realiza una aproximación al tema desde la relación discurso político - medios de comunicación y su impacto en las agendas gubernamentales, con fundamento en algunas obras del mismo autor, así como de otros autores que trabajan el tema, a su vez, para enriquecer el análisis se han seleccionado algunas situaciones relacionadas con políticas públicas y grupos minoritarios que son de actualidad tanto en Estados Unidos como en Europa a fin de dar fuerza a los argumentos expuestos.

No se busca hacer un análisis de la metodología utilizada por los analistas del discurso, sólo utilizar sus hallazgos para mostrar los efectos de texto y hablar sobre las políticas que afectan a muchos grupos minoritarios en países democráticos.

* El presente artículo de reflexión, trata sobre el discurso de las élites, realizado por Teun A. Van Dijk, a partir de la incidencia directa de las políticas públicas, sobre los diversos grupos minoritarios en países democráticos, tanto en Estados Unidos como en algunos países de Europa. 


\section{"RACISMO Y DISCURSO DE LAS ÉLITES” de TEUN A. VAN DIJK.}

\section{Contexto de la obra}

La citada obra de Teun Van Dijk es producto de una investigación sobre análisis del discurso en Estados Unidos y algunos países de Europa llevada a cabo por el autor entre 1980 y 1990 . Se trata de una etapa crucial ya que en ella se da el proceso de desintegración de la URSS con la consecuente proliferación de nuevos países en el este de Europa que abre las posibilidades de unificación de los mismos a la Unión Europea, a la vez, que se dinamizan nuevos "miedos" ahora por el fenómeno de la inmigración masiva. Si bien, hay un desplazamiento hacia la derecha luego de la caída del comunismo no obstante, para entonces, el racismo no estaba tipificado como delito.

En Estados Unidos a pesar de considerarse superada la etapa de reivindicaciones en torno a los derechos civiles y políticos de la población de color, sobreviven en la práctica expresiones de discriminación, esfera ahora ampliada con los nuevos contingentes de inmigrantes latinoamericanos que buscan posibilidades de trabajo en dicho país.

Este nuevo escenario experimenta ciertas transformaciones, pues ya no se trata del colonizador que va y aplica políticas racistas y de explotación en la población nativa como sucedía a finales del s. XIX y primera mitad del XX, se trata de personas que agobiadas por diversos tipos de violencia estructural buscan desesperadamente llegar a los países de mayor desarrollo económico en busca de oportunidades dada la demanda de mano de obra en dichas zonas.

Cuando Van Dijk culmina esta obra en 1992 se sucede con mayor fuerza en Europa y Estados Unidos, la emergencia de organizaciones extremistas, xenófobas, y en el campo político cobran fuerza partidos de derecha que tendrán responsabilidad por acción u omisión en las políticas sobre minorías, se trataba de un periodo histórico que hoy en pleno año 2008 tiende a perpetuarse.

Según la línea de sus trabajos precedentes, Teun Van Dijk (2004)1, utiliza el análisis crítico del discurso como herramienta metodológica. Se dedica a estudiar el discurso de la élite (políticos, ejecutivos, académicos, editores) en Estados Unidos, Inglaterra, y Holanda. Es decir, su objeto de investigación se centra en

\footnotetext{
"El Análisis Crítico del Discurso está relacionado con el poder y el abuso de poder y cómo éstos son producidos y reproducidos por el texto y el habla. El Análisis Crítico del Discurso se enfoca en los grupos e instituciones dominantes y en la forma en la que éstos crean y mantienen la desigualdad social por medio de la comunicación y el uso de la lengua. El ACD también centra su atención en la forma en la que los grupos dominados se resisten y oponen discursivamente a dicha dominación. El ACD no es un tipo de método ya establecido de análisis del discurso; se trata más bien, de una perspectiva o actitud crítica enfocada hacia problemas sociales importantes", p. 6.
} 
las dimensiones discursivas del racismo de élite y, por ello, acude a los debates parlamentarios, editoriales y noticias de prensa, análisis de textos de enseñanza y otros documentos de carácter público.

El estudio no pretende medir la frecuencia, sino "lo que dice y cómo lo dice" la élite cuando trata de expresar cuestiones étnicas (Van Dijk, 2003, 97). Pretende demostrar que el dominio étnico y el racismo siguen siendo un problema central en la sociedad occidental de hoy, por ello, el espacio de investigación seleccionado son algunos países de Europa y Estados Unidos.

Se utiliza un enfoque multidisciplinar ya que para poder dar cuenta del contexto específico en el que un racista se expresa se hace necesario un diálogo con la ciencia política, la antropología, la psicología social y la sociología.

El texto pretende mostrar que el racismo no consiste únicamente en las ideologías de supremacía racial que se expresan en agresiones evidentes (que hasta los racistas rechazan), también implica opiniones, actitudes e ideologías de la cotidianidad, es decir, el contexto cultural y social del racismo.

Por ello, el autor busca analizar las dimensiones discursivas más sutiles del racismo de élite que ayudan a la construcción del "consenso étnico dominante", es decir, aquellas que en general la élite se niega a llamar racismo. Y aunque los menciona, no pretende profundizar en los rasgos estructurales del racismo (desempleo, segregación de hecho, mala escolarización, marginación cultural) sino en aquellas sutilezas del racismo que pueden parecer inofensivas.

Para el autor, la gente común tiene un papel pasivo frente a los eventos discursivos controlados por las élites, por ello, su hipótesis se centra en la idea de que "las élites son las principales responsables de forjar los cimientos de producción e interpretación constituyendo el consenso étnico y justificando el racismo estructural" (Van Dijk, 2003, 30). Es decir, los prejuicios del racismo popular están preparados por las élites, se trata de un proceso "top down" por el acceso preferente de los que están arriba para la reproducción de prácticas racistas.

\section{Análisis del discurso de élite}

El siguiente Esquema 1 sintetiza las nociones tenidas en cuenta por Teun Van Dijk y en el Cuadro 1, se especifican dichas nociones expuestas en su obra para una mayor comprensión del modelo teórico y su propuesta metodológica. 
Esquema 1. Nociones para el análisis del discurso de Élite

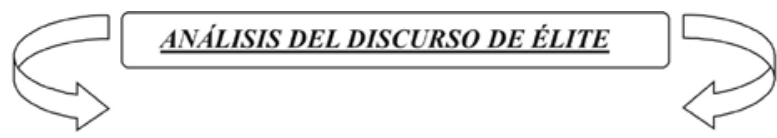

\begin{tabular}{|c|c|c|c|}
\hline GRUPOS & DOMINIO & RACISMO & $\begin{array}{l}\text { PRÁCTICA } \\
\text { SOCIAL }\end{array}$ \\
\hline D & C & $\mathrm{R}$ & $\mathrm{O}$ \\
\hline ÉLITE & IDEOLOGÍA & $\begin{array}{l}\text { RACISMO } \\
\text { BLANCO }\end{array}$ & $\begin{array}{c}\text { COGNICIÓN } \\
\text { SOCIAL }\end{array}$ \\
\hline $\begin{array}{l}\text { "Grupos sociales } \\
\text { que disponen de } \\
\text { recursos de } \\
\text { poder } \\
\text { especificos". } \\
\text { Toman } \\
\text { decisiones y } \\
\text { ejercen control. }\end{array}$ & $\begin{array}{c}\text { Otorga } \\
\text { coherencia al } \\
\text { sistema y al } \\
\text { desarrollo de las } \\
\text { actitudes. }\end{array}$ & $\begin{array}{l}\text { Predominio } \\
\text { europeo de grupo } \\
\text { hacia pueblos } \\
\text { con diferencias } \\
\text { físicas, } \\
\text { culturales y } \\
\text { socioeconómicas. }\end{array}$ & $\begin{array}{c}\text { Prejuicio no sólo } \\
\text { como actitud } \\
\text { individual sino } \\
\text { como prácticas } \\
\text { cotidianas de } \\
\text { grupo } \\
\text { institucionalizadas } \\
\text { o no. }\end{array}$ \\
\hline
\end{tabular}

Elaboración propia con fundamento en Cap. 2 "Racismo

y Discurso de las Élites” de Teun Van Dijk.

Cuadro 1. Nociones fundamentales para el análisis del discurso de élite.

\begin{tabular}{|c|c|}
\hline Nociones & \multicolumn{1}{c|}{ Implicación } \\
\hline Grupo & $\begin{array}{c}\text { La naturaleza intergrupal es una dimensión primordial del } \\
\text { racismo, el análisis del racismo tiene que ver con procesos de } \\
\text { reproducción de grupos. }\end{array}$ \\
\hline Poder & O $\begin{array}{l}\text { La reproducción del racismo sirve para mantener el poder del } \\
\text { grupo blanco, el poder de grupo es una forma de control del } \\
\text { grupo dominante sobre el dominado. }\end{array}$ \\
\hline Racismo & $\begin{array}{l}\text { El término racismo denota formas de etnicismo - dominio del } \\
\text { grupo que se fundamenta en la construcción o percepción de } \\
\text { diferencias culturales -, la apariencia y el origen suelen ser } \\
\text { los principales criterios de diferenciación de grupo, pero } \\
\text { pueden existir otros. El hecho de que, incluso los inmigrantes } \\
\text { totalmente integrados no puedan, por ejemplo, nunca ser } \\
\text { "realmente franceses" pone de manifiesto que estas actitudes } \\
\text { racistas no conciernen a la cultura sino a la raza. }\end{array}$ \\
\hline
\end{tabular}




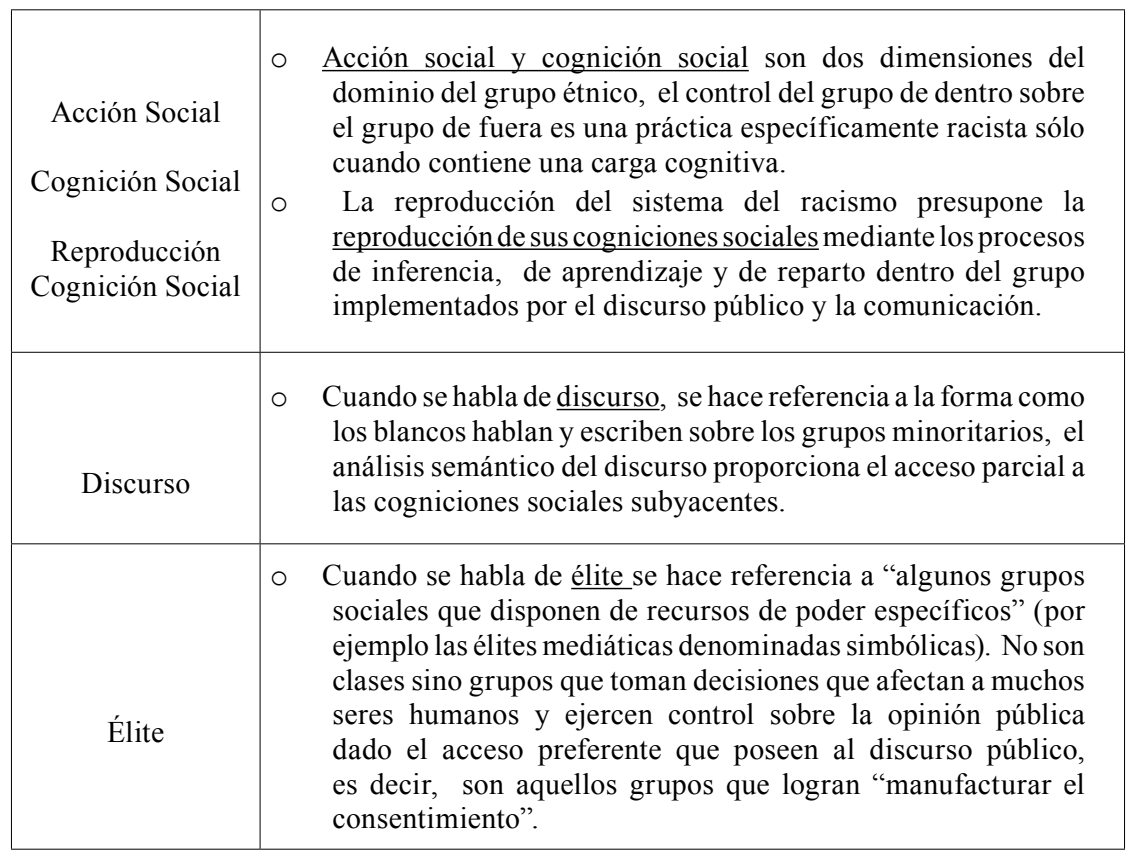

\section{Sobre el discurso político}

Del análisis de las diversas fuentes especialmente de los debates parlamentarios expuesto por el autor (Van Dijk, 2003) ${ }^{2}$, se pueden evidenciar los siguientes aspectos que afectan a las minorías en Occidente:

1. Existe un preocupante crecimiento de partidos racistas que utilizan el discurso xenófobo para ganar electores. Los políticos no combaten el racismo, convencidos de que la acción positiva hacia la inmigración, "podría costarles muchos votos blancos". Además, reciben la influencia de académicos y expertos, así como cuentan con la poderosa influencia de los medios.

2. La proliferación normativa contra el racismo sólo ha servido para suavizar el estilo de predominio de los blancos. Más que los tratados internacionales, han sido los movimientos de resistencia los que han logrado hasta cierto grado contener las actitudes racistas occidentales.

2 Las ideas centrales del análisis del discurso político que aparecen en el texto se han extraído de las páginas: $22,26,80,83,99$ y 155 
3. En el ámbito de los asuntos étnicos son principalmente los políticos quienes definen la situación étnica y fijan tanto los términos y límites del debate público, como la formación de opinión.

4. El verdadero antirracismo es coherente en todos los contextos y está sustentado por argumentos, por ello, se puede saber cuándo el discurso antirracista es utilizado como estrategia de campaña electoral.

5. Los políticos rechazan las acusaciones al ser considerados "racistas" ya que equiparan racismo con superioridad de la raza blanca, más exactamente con lo sucedido en el Tercer Reich, por ello, la palabra "no debe pronunciarse".

Pero lo expuesto anteriormente se sucede gracias a las estrategias del discurso político (Van Dij, 2003) ? $^{3}$ que han sido resumidas en el Cuadro 2:

Cuadro 2. Estrategias del Discurso Político

\begin{tabular}{|c|c|c|}
\hline $\begin{array}{c}\text { Exculpación: } \\
\text { Apelar a la retórica } \\
\text { nacionalista }\end{array}$ & $\begin{array}{c}\text { Presentación negativa } \\
\text { del inmigrante }\end{array}$ & $\begin{array}{c}\text { Mostrar al blanco } \\
\text { como víctima de la } \\
\text { discriminación }\end{array}$ \\
\hline $\begin{array}{c}\text { Asumir el papel } \\
\text { paternalista: }\end{array}$ & $\begin{array}{c}\text { Mostrar que la } \\
\text { inmigración genera } \\
\text { resentimiento popular }\end{array}$ & $\begin{array}{c}\text { Mostrar las cifras } \\
\text { fuera de contexto }\end{array}$ \\
\hline
\end{tabular}

Fuente: La autora

\section{El discurso corporativo}

Así como los políticos tiene sus propias estrategias para reforzar el discurso contra las minorías, los empresarios también las poseen, Van Dijk muestra que el discurso político sobre temas étnicos se alimenta del discurso corporativo y viceversa, se exponen a continuación (Van Dijk, 2003) ${ }^{4}$, las dimensiones discursivas sutiles propias del sector corporativo en Holanda y que es posible encontrarlas en las prácticas de contratación y de ascenso o promoción principalmente:

3 Las estrategias del discurso político se encuentran explícitas en el texto en las páginas 113, 114, $124,129,131,137,141,155$ y 285

4 Con base en lo expuesto por el autor en las páginas 163, 170, 173, 174, 204, 286 y 287 
1. Rechazo a la acción afirmativa. Se afirma que el mundo empresarial no discrimina "no mira el color de la piel", se concentra en las capacidades por lo que no deben ser considerados una agencia de bienestar social.

2. Los inmigrantes no están capacitados; según el discurso corporativo los inmigrantes tienen falencias lingüísticas y de nivel educativo, por lo que los empresarios culpan al Estado por no prepararlos adecuadamente para poder competir en el mercado laboral.

3. Invisibilidad en el discurso público, los gerentes prefieren evadir el pronunciarse sobre asuntos étnicos.

4. Centrar el discurso en los deberes de las minorías y no en sus derechos.

5. Mostrar que hacen todo lo que pueden por ayudar a integrar laboralmente a las minorías.

Según el autor, los gerentes europeos "no están bien preparados para gestionar la multiculturalidad obrera del futuro". A su vez, los procedimientos de contratación y de empleo terminan por excluir a las minorías, tal vez, Estados Unidos ha mostrado cierto avance en políticas de acción afirmativa si se le compara con Europa.

\section{El discurso desde la educación}

En este punto, el autor (Van Dij, 2003) ${ }^{5}$ hace ver cómo, luego de la Segunda Guerra Mundial el discurso académico se ha mantenido al margen de las explicaciones que apoyaban prácticas racistas, pero aún se suceden situaciones más sutiles especialmente desde la socio-biología neo-darwinista y la psico-biología. Veamos a continuación los aspectos más relevantes que se pueden extraer desde el discurso académico: a) En los años ochenta del siglo pasado en los libros de texto de enseñanza se describían las relaciones étnicas desde una perspectiva blanca euro-céntrica o las minorías eran ignoradas por completo, b) Por fortuna son cada vez más frecuentes los textos que representan las minorías étnicas como parte de un sistema generalizado de educación multicultural, sobre este particular Van Dijk sugiere no permanecer en los simples temas de carácter "folklórico", sino en la necesidad de que los niños blancos compartan las experiencias cotidianas de sus compañeros de otras culturas, c) Se señala la poca neutralidad de algunos textos de enseñanza en Holanda que subrayan las diferencias de los grupos étnicos con relación a la población nativa lo que crea ciertos estereotipos, d) Al analizar algunos textos de sociología tanto en Estados Unidos como en Inglaterra encuentra que textos de autores como Sanderson o Anthony Giddens (1998) con la utilización frecuente de eufemismos, la ocultación, la presentación de la discriminación como en hecho "universal", hace que se ignoren los mecanismos cotidianos del racismo.

5 El análisis sobre el discurso desde el ámbito académico-educativo se encuentra en el texto referenciado en las páginas 212, 215, 218, 229 y 287. 
A pesar de los esfuerzos de algunos sectores por impartir una educación más incluyente, "los escolares de hoy no están preparados para un futuro dentro de una sociedad contemporánea diversa como lo son la norteamericana y europea $y$, por otra parte, no están sensibilizados contra las modalidades predominantes de racismo cotidiano".

\section{El discurso mediático}

El poder que tienen los medios en la formación (Van Dij, 2003) ${ }^{6}$ del consenso de élite con relación a la representación cognitiva de los grupos minoritarios, según el autor, es indiscutible y lo muestra a través de aspectos que se concretan en el Esquema 2.

El papel de la prensa no es pasivo, no es el de informar simplemente sobre asuntos étnicos, según Van Dijk, disfruta de un importante grado de autonomía, de poder $\mathrm{y}$, al ser negocio de blancos "tiene la misión moral de representar la causa de su propio grupo". Dado lo anterior, la solución no vendrá de los blancos pues no existe una resistencia eficaz contra el consenso dominante -bajo impacto de los medios informativos alternativos-, será necesario que los propios grupos minoritarios tomen la iniciativa cuando se trate de informarse de los asuntos que les competen como lo han empezado a hacer los colectivos de mujeres.

Esquema 2. El discurso mediático

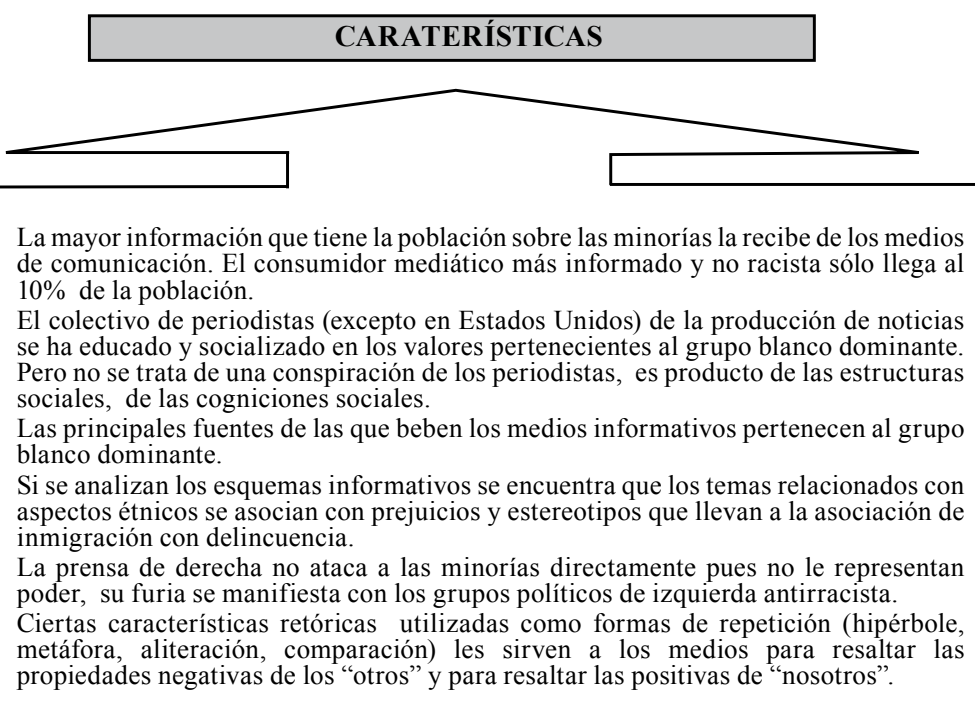

6 Los argumentos con relación al discurso de los medios de información se hallan expuestos en la obra en las páginas 234, 237, 244, 256, 258, 259, 261, 281 y 282. 
Si se analiza detenidamente el párrafo anterior, Teun Van Dijk sólo hace una breve mención sobre el rol que deben desempeñar los grupos minoritarios frente a la situación de discriminación que se presenta y esto se debe a que su hipótesis de trabajo gira precisamente en torno al papel pasivo que tienen dichos grupos frente al aplastante poder de los grupos controladores de los cuales las minorías no hacen parte. Por ello, durante toda la obra trata de demostrar que el proceso de formación sobre el "consenso étnico" viene de arriba abajo mediado por la reproducción de las cogniciones sociales y mientras siga la relación "top down" las prácticas racistas seguirán imponiéndose.

\section{EL DISCURSO POLÍTICO Y MEDIÁTICO RACISTA OBSTÁCULO PARA LA CONSTRUCCIÓN DE POLÍTICAS PÚBLICAS MULTICULTURALES ${ }^{7}$}

Los textos de Van Dijk despiertan el interés por analizar el impacto del discurso de élite sobre las políticas públicas ${ }^{8}$ que tienen relación con la acción o inacción de los gobiernos con relación a la gestión de la multiculturalidad, es decir, con el multiculturalismo que aparece ya como una clara necesidad al interior de Europa y Estados Unidos dado el rápido crecimiento de conflictos vinculados con la diversidad cultural al interior de los países con mayor desarrollo económico.

No se pretende abordar la metodología de análisis del discurso trabajada por Van Dijk y otros autores, sólo tomar los elementos esbozados en sus obras desde el discurso de élite que permiten enlazar el ámbito público y mediático en torno a su influencia sobre la construcción de las agendas gubernamentales que afectan directamente a diversos grupos étnicos minoritarios en Europa y Estados Unidos. El interés por abordar esta temática radica en la implicancia que tiene el racismo,

7 Se consideran políticas multiculturales, aquellas inspiradas en el ideal ilustrado de la tolerancia como virtud pública - buscan viabilizar el principio de la igualdad y el principio de la diferencia del liberalismo político: en: "Interculturalizando el Multiculturalismo". p. 5. http:/www.cidob.es/castellano/publicaciones/monografias/intercultural/tubino.pdf

8 Es la acción de la autoridades públicas en el seno de la sociedad y se transforma a su vez en un programa de acción de una autoridad pública (Meny y Thoenig, 1995); está constituida por las acciones gubernamentales - lo que los gobiernos dicen con relación a un problema o a una controversia (Dubnick, 1983). "Para que una política pública pueda ser considerada como tal, es preciso que en un cierto grado haya sido producida o, por lo menos, tratada al interior de un marco de procedimientos, de influencias y de organizaciones gubernamentales" (Hogwood, 1984). "Una política pública designa el proceso por el cual se elaboran y se implementan programas de acción pública, es decir, dispositivos político-administrativos, coordinados en principio, alrededor de objetivos explícitos" (Muller y Surel, 1998). "Lo que el gobierno opta por hacer o no hacer" (Thomas Dye, 1982). La política pública es un tipo de actividad del gobierno, aquella que se encamina a estimular la colaboración social o inhibir el conflicto, es el cauce que determina y orienta el curso de la actividad gubernamental (Omar Guerrero, 1992). 
entendido como poder, para miles de grupos minoritarios que han de pagar el precio de la mala política manifiesta a través del sufrimiento humano.

\title{
Poder y Racismo
}

\author{
"La definición de racismo implica, más que \\ una relación de raza, una forma de poder \\ $y$, sobre todo, (...) es una forma de abuso de \\ poder del grupo dominante blanco. A ese tipo \\ de abuso de poder lo llamo dominación".
}

(T. Van Dijk)

Analizar el fenómeno del racismo más allá del enfoque meramente sociológico, implica abordarlo a su vez, desde el ámbito del poder, la ideología, la dominación, que lleva a un grupo de actores dominantes a considerar que el trato discriminador hacia las minorías es "normal" o "legítimo".

Los estudios de los lingüistas como Teun Van Dijk y Ruth Wodak ${ }^{9}$, en relación con el racismo nos remiten al concepto de poder asimétrico, o "poder sobre", según Steven Lukes $(2007,83)$, ese poder es la capacidad de conseguir una serie determinada de resultados, entre ellos los comprendidos por el concepto de dominación. Es decir, la capacidad de la élite política y mediática para lograr imponer a través de texto y habla unas creencias determinadas sobre las minorías a los grupos mayoritarios de la población en Europa y Estados Unidos, y que por sus efectos en el plano gubernamental (apoyo electoral a partidos con inclinaciones racistas), logran incidir sobre las políticas públicas.

9 Esta autora utiliza la metodología de análisis crítico del discurso para estudiar el neo-racismo en la Austria contemporánea. En su obra "se trata de gente que con sólo mirarla se adivina su origen: análisis crítico del discurso y el estudio del neo-racismo en la Austria contemporánea”, que escribe junto a Bern Matouscheck, se pregunta: “Somos los austriacos hostiles hacia los extranjeros?” “Ha sido la reacción pública hacia las llamadas "nuevas migraciones de población” de los nuevos estados europeos centro-orientales "liberados", inhumana y demasiado emocional, o ha sido esta respuesta una reacción defensiva que exigía una situación que amenaza la estabilidad social de nuestro país?" Así, los autores se proponen determinar la influencia específica que el discurso público, inmerso en la política y en los medios de comunicación, tiene realmente en las actitudes hostiles y comportamientos del gran público. El Análisis Crítico del Discurso puede llegar a develar cuestiones tales como: ¿Quién habla con hostilidad hacia los extranjeros? ¿A quién se refiere, cuándo y en qué escenario? ¿Qué actitud existe entre el contexto y los comentarios y qué efectos tienen dichas actitudes sobre otros? Los autores se responden por medio del análisis de las reacciones sociales y políticas dentro de Austria frente a las migraciones provenientes de Europa del Este, 1988-1990 de un breve estudio discursivo-histórico del neo-racismo en la Austria contemporánea, y del análisis de la perspectiva del discurso analítico del prejuicio, entendido este último como "una aversión basada en una generalización intolerante e incorrecta, que puede sentirse o expresarse ante un grupo en su totalidad o ante un individuo por ser parte de ese grupo" y al que se le dedican varias páginas, en: In L.M. Rojo \& R. Whittaker (eds.), Poder decir o el poder de los discursos. Madrid: Arrecife, p. 55-92. 
El punto de partida necesariamente se encuentra en la forma como Van Dijk $(2003)^{10}$ concibe las ideologías, trabaja con un marco teórico alternativo en el que las ideologías se consideran "cogniciones sociales", esto es, un conjunto de creencias compartidas por un grupo, expresadas, reproducidas y legitimadas en la interacción social mediante mecanismos discursivos. Por ello, son los grupos sociales los que tienen y aprenden ideologías y no los individuos en su condición de sujetos particulares, alrededor de nuestros esquemas ideológicos básicos se organizan un conjunto de actitudes y prejuicios que dan forma a nuestras representaciones sociales, sería lo que Castells (1997) denomina como identidades legitimadoras, que son "introducidas por las instituciones dominantes de la sociedad para extender y racionalizar su dominación”.

Para poder comprender el poder de la Ideologías (Van Dijk, 2003, 14) ${ }^{11}$ racistas (implica múltiples prejuicios) contra las minorías étnicas que tanto en Europa como en Norteamérica toman cada vez más fuerza, es importante resaltar el papel de la ideología como fundamento de las prácticas sociales. Es decir, las ideologías forman la base de las prácticas de los miembros de un grupo dominante, aquellas "proporcionan los principios con qué justificar, legitimar, condonar o aceptar el abuso de poder (...) son (...), la fuente y el resultado de las prácticas del grupo y, por lo tanto, conducen a la perpetuación del grupo y de su poder" (Van Dijk, 2003, 48); en consecuencia, se establece el principio que le permite a un grupo merecer ciertas ventajas con relación a otros grupos.

Este poder de grupo se manifiesta directamente sobre el control del ciudadano, del receptor, a manera de ejemplo, Danilo Zolo observa la profunda asimetría que se sucede en el "rol comunicativo" entre el que emite y el que recibe el mensaje: "El primero selecciona los contenidos (efecto agenda) silencia lo que no le es grato (nueva censura) e inyecta en el público los propios registros selectivos. Por el contrario, el segundo, que además desconoce el iter a través del cual se elabora el producto - noticia y se percibe de modo desagregado, termina enajenando su autonomía y potencial cognitivo"12 (Zolo 97, 1997, 30). Pero la incidencia directa de los medios se filtra por un importante factor, su poderoso papel en la construcción de nuestras imágenes de la realidad, de las cuales se retroalimentan los líderes políticos para realizar sus campañas electorales, se trata de un proceso cíclico de cogniciones entre las cuales el discurso racista juega un papel importante.

Recordemos que "la inmensa mayoría de estructuras de discursos diferentes no sirven únicamente para representar de forma estratégica, expresar, señalar, disfrazar, subrayar o legitimar una posición social y, por tanto, el poder del orador, sino también para controlar a voluntad el pensamiento del receptor" (Van Dijk,

10 En su obra "Ideología y Discurso" (2003), aborda explícitamente las connotaciones de la ideología como sistema de creencias y su implicancia dentro del racismo.

11 Para Van Dijk las ideologías "son las creencias fundamentales de un grupo y de sus miembros".

12 Zolo, D. (1997). Retomado por Ramón Vargas Machuca en: Bonapartismo Mediático y Democracia Defectiva. Revista Claves de Razón Práctica No. 115. p. 30. 
1997, 24). Por ejemplo, en relación a lo que pasa en la actualidad con las noticias sobre minorías, el lector recuerda principalmente el contenido de los titulares de prensa $^{13}$, los cuales, a su vez, definen subjetivamente una situación: "italianos cansados de ilegales"14 o son objeto del pánico público que pueden generar ciertas noticias: "Miedo a la Inmigración"15.

Pero con relación a este cierto "control" sobre el receptor nos preguntamos: ¿Qué es lo que hace que en los últimos años de esta primera década del siglo XXI, hablemos de la enajenación de los ciudadanos a los poderes político y mediático, hacia ideas cargadas de prejuicio y exclusión hacia los extranjeros, cuando se supone que nos encontramos en la etapa de mayor ampliación de los derechos civiles y políticos? Existe un factor que puede explicar en parte este fenómeno y obedece a que las personas que se sienten inseguras, las personas preocupadas, por lo que pueda deparar el futuro y que temen por su seguridad, no son verdaderamente libres como para escapar de la explosión mediática que envuelve sus vidas en la cotidianidad.

El anterior argumento es defendido por Zygmunt Bauman $(2002,24)$ quien afirma que cuando reina la inseguridad la única manera de alcanzar la solidaridad comunitaria es por medio de la elección de un enemigo común y, a la luz del análisis del discurso develado en la primera parte de este trabajo, hablaríamos de las minorías, ello explicaría la frialdad hacia los inmigrantes, gitanos, judíos y demás grupos asentados a lo largo de Estados Unidos y Europa. Para el caso español, por ejemplo, el porcentaje de personas que muestran actitudes hostiles hacia las personas inmigrantes se ha incrementado del 8 al 32\% de 1997 a 2004 y de modo particularmente destacado desde el año 2000. A su vez, el $60 \%$ de la población parece asociar la inmigración con la delincuencia. Así, al explotar miedos tradicionales y al utilizar a las personas inmigrantes como chivos expiatorios de diversos problemas sociales, se exacerba la discriminación, el racismo y la xenofobia (Informe Amnistía Internacional, 2008, 15). El "consenso étnico" se ha construido a lo largo del tiempo en un proceso de "reproducción de las cogniciones sociales" bajo el fuerte impulso del discurso político y mediático.

\section{La doble interrelación discurso político - discurso mediático}

Estrategias como las del discurso político explícitas en el Cuadro 2 de la I parte, dificultan el consenso sobre políticas multiculturales pues obedecen a la gran asimetría de información y manejos de asuntos políticos entre los agentes políticos mediáticos y los ciudadanos.

13 Esto es así fundamentalmente por la enorme y creciente cantidad de información que nos llega en la vida diaria, nos encontramos con miles de noticias, símbolos, declaraciones, imágenes e incitaciones de casi cualquier índole a través de los medios.

14 Titular de Minuto Digital, 1 de Abril de 2008. http://www.minutodigital.com

15 Titular de Nuevo Siglo, 22 de Octubre de 2004. http://www.minutodigital.com 
Se trata de develar lo que Manin $(1995,279)$ denomina "democracia del público" para referirse al tipo de sistema político que está en etapa de transformación y que se encuentra construyendo "nuevas comunidades de emoción", que tiene un efecto directo sobre las minorías toda vez que han pasado a ser uno de los temas centrales dentro de la ocupación mediática del espacio político de la representación. Así, por ejemplo, en el caso de Italia desde el mes de octubre de 2007, "políticos y medios de comunicación italianos han llevado a cabo una campaña contra los gitanos de origen rumano residentes en Italia,....la tensión se agravó tras el anuncio del paquete de medidas sobre la seguridad del Ejecutivo Berlusconi"'16. Este efecto del discurso político - mediático analizado por los lingüistas, es corroborado, en el informe para el caso español de Amnistía Internacional, al considerar que el discurso que realizan autoridades públicas, políticos y medios de comunicación, influye notablemente en la percepción pública de las personas inmigrantes y sus derechos:

"Así, por ejemplo, el Centro de Investigaciones Sociológicas (CIS) realizó una encuesta a finales del 2005 que medía, entre otras cuestiones, la tolerancia hacia diversos colectivos sociales. A más del $40 \%$ de los entrevistados les molestaría mucho o bastante si tuvieran como vecinos a personas gitanas. Al $25,3 \%$ de la población española les importaría mucho o bastante que sus hijos e hijas compartieran en el colegio la misma clase con niños de familias gitanas. Un 9,9\% mostraba el mismo grado de preocupación respecto a los niños y niñas de familias inmigrantes extranjeras. En julio de 2006, coincidiendo con la utilización de determinadas expresiones por los medios de comunicación - avalancha, invasión, aluvión (..).- para informar de la entrada de inmigrantes por la frontera sur de España, el $35,9 \%$ de los encuestados dijo que la inmigración era el principal problema, sólo por detrás del paro $(46,8 \%)$. En el barómetro publicado en diciembre del 2007 por el CIS, aunque sólo un $0,4 \%$ percibía el racismo como un problema, el $26,9 \%$ de los encuestados consideraba a la inmigración es percibida como el principal problema que existía en España” (Informe Amnistía Internacional. Op. Cit, p. 14 - 15).

Si se tiene en cuenta el grado de autonomía que poseen, el papel de la prensa no es pasivo, afirma Van Dijk, se trata de una élite simbólica que construye su propia agenda y a través del proceso de creación de opiniones contribuye a la interpretación de la realidad, que aplicada a la nota textual anterior revela que la inmigración constituye todo un "problema" que genera respuestas provocadas por un proceso de aprendizaje en el que el discurso público ha sido determinante. En este sentido, Manuel Castells (1998) ve la relación de interrelación políticos - medios de forma asimétrica dando mayor poder a estos últimos y considera que en el proceso de

16 La Mano dura de Italia contra la inmigración, alarma a Europa, en: La Vanguardia, Barcelona, 15 de Mayo de 2008. 
globalización, la producción de imágenes, sonidos e información tiende cada vez más a escapar del control del Estado en la medida en que los políticos necesitan en mayor medida de los medios de comunicación que en el caso inverso.

La dispersión y abundancia de mensajes, la preponderancia de los contenidos de carácter comercial y particularmente propagados por grandes consorcios mediáticos y la ausencia de capacitación y reflexión suficientes sobre estos temas, suelen aunarse para que en la Sociedad de la Información el consumo prevalezca sobre la creatividad y el intercambio mercantil sea más frecuente que el intercambio de conocimientos (Trejo, 2001). Entonces, sumado a las inseguridades de las que habla Barman, descritas con anterioridad: ¿Podría pensarse que el activo papel de los medios en la formación de nuestras cogniciones sociales tiene un efecto directo sobre la mínima presencia de ciudadanos críticos frente a los discursos públicos que impulsan el racismo?

\section{Los efectos de la negación del racismo desde el discurso de élite sobre las políticas públicas}

Van Dijk encuentra que los políticos rechazan las acusaciones de ser considerados "racistas" ya que equiparan racismo con superioridad de la raza blanca, de ahí su rechazo al término, ${ }^{17}$ veamos este aspecto con mayor detenimiento.

En la actualidad la élite en el poder entiende racismo como racismo biológico que predominó desde finales del siglo XVIII hasta 1945 y que se caracterizaba por una lucha natural de razas (Torrens, 1998,306$)^{18}$ por ello no acepta que se le incrimine como racista ya que se considera una etapa "superada" luego del "Holocausto Judío"; es decir, aún no se ha reconocido entre importantes sectores políticos la existencia del racismo cultural, es decir, aquel que enfatiza en "la identidad cultural percibida como propia y nunca se autocalifica de racista pero es evidente que esconde estructuras de dominio y explotación” (Op. Cit. 310).

Esta negación del racismo ha significado una estrategia eficaz dentro del grupo de decisores públicos que tiene un matiz más acentuado si el gobierno en el poder es ideología de derecha. Pero no sólo la élite política manifiesta esta negación, los empresarios al rechazar la acción afirmativa con el argumento de que en el mundo empresarial no se discrimina, que: "no mira el color de la piel", sino que se

17 Un caso al respecto lo protagonizó el gobierno de Italia cuando el 16 de mayo último la Vicepresidenta primera del Gobierno de España descalificó las medidas de aquel contra los gitanos en Roma por considerar que fomentaban la xenofobia y el racismo, indignado el gobierno italiano solicitó rectificación por haber utilizado este término para referir lo que sucedía con las políticas contra la inmigración ilegal en dicho país. Web: http://www.elmundo.es/accesible/elmundo/2008/05/16/ espana/1210967418.html

18 Arendt, retomada por Xavier Torrens. (1998). "Racismo y Antiracismo", en: Ideologías y Movimientos Politicos Contemporáneos, de Joan Antón Mellón (ed). Madrid: Tecnos. p. 306. 
concentra en las capacidades de los individuos, desconoce la realidad del trabajador inmigrante.

Esa negación de la existencia del racismo por parte de la élite política, mediática y empresarial es una forma invertida que dice tolerar la identidad del otro, concibiéndolo como una comunidad cerrada hacia la cual, el multiculturalista mantiene una distancia que se hace posible gracias a su posición universal privilegiada, por ello, se afirma que "la tolerancia multiculturalista por la especificidad del Otro es precisamente la forma de reafirmar la propia superioridad, la neutralidad multiculturalista es falsa. Éste no es directamente racista, no opone al Otro los valores particulares de su propia cultura, sino que pretende afirmar la coexistencia híbrida de mundos culturalmente diversos ocultando la problemática real: la presencia masiva del capitalismo con su consecuente imaginario"'l9, se trata de una contradicción del propio proyecto liberal -democrático.

Así, la negación del racismo afecta las políticas públicas no tanto por acción como por omisión, recordemos que éstas operan en función de una situación problemática y si el problema no existe para los decisores públicos no tiene por qué agendarse y menos definir metas y estrategias de implementación. El efecto directo es el "silencio", la no acción que puede ser tan perjudicial para las minorías como lo pueden ser las prácticas directas de xenofobia que experimentan.

Si existe visibilidad del "problema" de las minorías, ésta da por lo que se ha considerado un efecto de su presencia, la inseguridad de la que los ciudadanos exigen respuestas al gobierno, pero no porque las minorías en sí mismas demanden atención como seres humanos. Este es un obstáculo no sólo en Europa y Estados Unidos, en Latinoamérica según el "latinobarómetro", una de las mayores dificultades para la integración regional es el rechazo hacia los grupos minoritarios así, "siete de cada diez latinoamericanos está en desacuerdo con que personas no nacionales, pobres o de distinta raza vivan en su país" ${ }^{20}$, como vemos se trata de un problema global que demanda una rápida respuesta desde las agendas gubernamentales y sobre todo desde medidas de acción afirmativa dadas las implicaciones que tienen tanto para aquellos que se encuentran en situación de desigualdad manifiesta por su situación de pobreza, como para los que son excluidos por su condición de pertenencia a una minoría.

Este fenómeno de la invisibilidad del racismo se expresa en un aspecto que si bien no es tratado directamente en la obra de Van Dijk, tiene repercusiones en la agenda pública, se trata del intento por "homogeneizar" desde el discurso a las minorías, lo que constituye una especie de "universal abstracto" que impide incluir las diversas perspectivas valorativas de la pluralidad de nacionalidades que se encuentran en el

19 Estrach, Nuria. La Máscara del multiculturalismo, en: Scripta Nova No. 94, 1 agosto. Revista electrónica Web: http://www.ub.es/geocrit/sn-94-104.htm

20 El Latinobarómetro: Siete de cada diez latinoamericanos rechaza a inmigrantes”, en: El Espectador Bogotá, 17 de Abril de 2008. Página Actualidad. 
territorio de un Estado determinado. Veamos un caso, el Ministro Italiano de Política Comunitaria ha negado al Secretario de Estado de la Unión Europea, Diego López Garrido que su Ejecutivo ampare conductas racistas, pero ha asegurado que será inflexible con los inmigrantes que pongan en riesgo la seguridad del país. "Una Italia más segura, más tranquila y más serena que cuente con una homogeneidad cultural como base de su acción política será una Italia más fuerte, más creíble y más convincente hacia Europa" 21 . Lo anterior va en contravía de la pretensión de las políticas multiculturales de viabilizar el principio de la igualdad y el principio de la diferencia, he aquí uno de los serios dilemas de la negación del racismo.

\title{
Incidencia del discurso político-mediático sobre la construcción de la agenda pública
}

\begin{abstract}
"Las élites tienen un papel y una responsabilidad especiales.
Sus discursos no son privados, sino públicos, y pueden afectar a millones de personas. Una palabra racista de un ministro en un titular de un diario puede hacer más daño que miles de conversaciones informales"

(T. Van Dijk)
\end{abstract}

El elemento "dominación" a través del discurso se constituye en un factor de poder, Van Dijk en "Racismo y Análisis Crítico de los Medios" hace ver cómo los políticos controlan el discurso gubernamental y parlamentario favorecidos por su acceso preferente a los medios de comunicación de masas y "en las sociedades industrializadas por consiguiente, los medios de comunicación son la institución principal de (re)producción ideológica, probablemente más importante que el sistema educativo propiamente dicho" $(1997,53)$.

Según Maxwell McCombs $(2006,25)$, la agenda de los medios informativos se vuelve en gran medida, la agenda pública, su papel como fijadores de la agenda consiste, principalmente, en incidir sobre la relevancia de un tema, así lo comprueba este autor en estudios que realiza en diferentes lugares del mundo cuando encuentra una relación causa-efecto entre la agenda mediática y la pública. En su análisis entre septiembre y noviembre una semana después de las elecciones presidenciales de Estados Unido en 1996, este autor comparó la frecuencia de discusión con el patrón de cobertura informativa de los principales diarios del país sobre cuatro temas: inmigración, sanidad, impuestos y aborto, concluye que "el debate sobre la inmigración respondió de manera inmediata a la cobertura informativa" (McCombs, 2006, 95-96) los demás temas necesitaron un margen de tiempo mayor.

21 España expresa a Italia el rechazo por convertir en delito la inmigración ilegal, en: La Vanguardia, 22 de mayo de 2008. Página Internacional. 
La agenda pública recoge las demandas ciudadanas, y éstas han sido permeadas por un proceso casi invisible de aprendizaje y si bien no todos colocan el mismo nivel de atención sobre lo que informan los medios, en general, los espectadores incorporan en sus demandas muchos de los hechos que se le presentan a sus imágenes y actitudes ${ }^{22}$, es decir, incorporan la agenda de los medios de comunicación en la suya propia, por ejemplo, en el caso anteriormente señalado, "el problema de la inmigración" constituía el principal tema de la agenda de los medios y así era percibido por los electores estadounidenses en aquel momento, según McCombs, situaciones como esta reflejan "que los medios de comunicación son profesores cuya principal estrategia comunicativa es la redundancia", los alumnos ciudadanos habrán de responder la lección y enunciar cuáles son los principales problemas de la nación.

Pero: ¿Por qué el fenómeno de establecimiento de la agenda por los medios se convierte en un obstáculo desde el punto de vista de las políticas públicas multiculturales? Fundamentalmente, porque, centran la atención en algunos temas y pasan por alto otros $\mathrm{y}$, al imponerse esta simplificación se cae en la exclusión, por lo que se tiende a "(...) dejar en penumbra zonas de la realidad que se ignoran y cancelar alternativas que se silencian. Además, se gobierna de tal manera para la "galería mediática" que la espectacularidad o el anuncio de una medida agota en sí mismo el interés y la virtualidad política de aquella” (Sánchez, 1996, 102-106), así, lo rápido e impactante (emoción) subordina el debate responsable, meticuloso, que tiene en cuenta el contexto, y deja aplazada la formación de consensos sobre políticas multiculturales.

A su vez, como vimos anteriormente, los atributos creados por los medios en las mentes de los receptores es muy fuerte, ya que no se hace de forma deliberada, existe una preparación previa de aquellos sobre los puntos de vista que guían la opinión pública. Por ello, en concordancia con los programas de los gobiernos de turno y a través de titulares, editoriales, mensajes cifrados y demás estrategias para tratar los temas relacionados con las minorías, los medios influyen no sólo en nuestras opiniones sino también en nuestra conducta, de ahí la proliferación de protestas y actos de violencia de algunos ciudadanos especialmente en Italia, Francia y Sudáfrica durante todo el año 2008, se trata de un problema que incide directamente sobre las políticas públicas nacionales y de carácter comunitario.

22 Un estudio realizado entre 1999 y 2002 sobre el tratamiento dado a los temas relacionados con inmigrantes por parte de los periódicos de mayor circulación en Cataluña concluye que, si bien, hay ciertos avances por mostrarse tolerantes "también hay postulados discriminatorios que destacan(...) la llamada implícita yen ocasiones explícita a incrementar el control de la inmigración; la aceptación de que la entrada debe estar restringida; la ausencia de voz politica de los inmigrantes; la sobrerepresentación de las posturas racistas; el uso de conceptos discriminatorios ('inmigración ilegal' y otros); la etnificación de la delincuencia y el hecho de destacar los elementos más crueles de los delincuentes inmigrantes; $o$, la reiteración de las informaciones sobre pateras y su presentación como oleada". Estudio de Giró, X; Jarque, J. citado en Zer: Revista de estudios de comunicación = Komunikazio ikasketen aldizkaria, No. 20. 2006. 


\section{EPÍLOGO}

Los lingüistas nos muestran desde el análisis crítico del discurso las dimensiones discursivas más sutiles del racismo de élite que ayudan a la construcción del "consenso étnico dominante", sus hallazgos nos dejan ver la complejidad que entraña el racismo cultural pues éste último adquiere formas menos visibles en el escenario de texto y habla tanto de las élites políticas como de las élites simbólicas (mediáticas).

Es importante tener en cuenta que el discurso político y su incidencia sobre el proceso de toma de decisiones en relación con asuntos étnicos, afecta tanto a los grupos mayoritarios como minoritarios, pero los decisores pertenecen a la cultura dominante lo que tiene un efecto directo en la construcción de políticas públicas sobre minorías.

La realidad nos muestra que si bien existen defensores de las propuestas antirracistas se trata de grupos minoritarios que no tienen el poder político y mediático para llegar a toda la población como si lo hacen los discursos que de forma sutil o abierta fomentan la discriminación y la xenofobia. Por ello, surgen propuestas desde el multiculturalismo de la equidad que buscan empoderamiento al interior de las minorías con miras a frenar su desagregación y fortalecer su presencia en la toma de decisiones públicas sobre los asuntos que directamente les afectan.

No se pretende negar el fenómeno de la inmigración sino replantear la actual utilización del discurso para reproducir una visión, por lo general, desproporcionada de lo que está sucediendo tanto con los que llegan como con las minorías ya asentadas de tiempo atrás en el territorio. Acercándonos al final de la primera década del Siglo XXI, podemos estar a las puertas de nuevas expresiones de la ideología racista, por ello, es importante estar alerta y apoyar las investigaciones que permitan dar cuenta de la visibilidad de las nuevas formas del discurso que, mediante estrategias cada vez más sofisticadas o sutiles, proporcionan argumentos para que los más débiles sean objeto de rechazo y, más concretamente, del impacto de dicho discurso sobre las políticas públicas que bien por lo que hacen o por lo que dejan de hacer provocan el sufrimiento de numerosos grupos étnicos en todo el mundo.

\section{REFERENCIAS}

Bauman, Z. (2002). En busca de la política. México: F.C.E.

Castells, M. (1997). La era de la información, economía, sociedad y cultura. Madrid. Alianza.

Castells, M. (1998). “¿Hacia el Estado red? Globalización económica e Instituciones Políticas en la era de la Información". Sao Paulo, BID.

Estrach, M. (2001). Nuria "La máscara del multiculturalismo", en: Scripta Nova No. 94, 1 agosto. Web: http://www.ub.es/geocrit/sn-94-104.htm 
Giró, X; Jarque, J. Prensa escrita e inmigración itado en Zer: Revista de estudios de comunicación = Komunikazio ikasketen aldizkaria, No. 20. 2006.

Informe Amnistía Internacional. (2008). "España: entre la desgana y la invisibilidad, políticas del estado Español en la lucha contra el racismo". Abril 4.

McCOMBS, M. (2006). Estableciendo la agenda: el impacto de los medios en la opinión pública y en el conocimiento. Barcelona. Paidós, Ibérica.

Lukes, S. (2007). El poder un enfoque radical. Madrid: Siglo XXI.

El Espectador, Bogotá, 17 de Abril de 2008.

Rojo, L.; Whittaker, R. (eds.). Poder decir o el poder de los discursos. Madrid. Arrecife.

Sánchez, S. (1996). Los medios de comunicación y los sistemas democráticos. Madrid. Marcial Pons.

Torrens, X. (1998). "Racismo y antiracismo", en: Ideologías y movimientos políticos contemporáneos - Joan Antón Mellón (de). Madrid: Tecnos.

Trejo, R. (2001). Vivir en la sociedad de la información, en: Revista Iberoamericana de Ciencia, Tecnología, Sociedad e Innovación OEI-UNAM, No. 1. Sep-Dic.

Van Dijk, Teun A. (1997). Racismo y análisis crítico de los medios. Barcelona: Paidós.

Van Dijk, Teun A. (2003). Ideología y discurso. Barcelona. Ariel.

Van Dijk, Teun A. (2003). Racismo y discurso de las Élites. Barcelona: Gesida.

Van Dijk. (2004). Ponencia: Ideología y discurso. Universidad Nacional de Colombia, Febrero.

Vargas, R. (2001). Bonapartismo mediático y democracia defectiva, en: Revista Claves de Razón Práctica, No. 115. Universidad de la Rioja, España 
